\title{
Effects of cyclooxygenase inhibitors on survival time in ovarian cancer xenograft-bearing mice
}

\author{
WEI LI, XIAO-LI XU, JUN ZHANG, JIA-HUI CAI and YUN-XIAN TANG \\ Department of Gynecology, Nanjing Medical University of Hangzhou Hospital, Hangzhou, Zhejiang 310006, P.R. China
}

Received June 27, 2012; Accepted September 12, 2012

DOI: $10.3892 / 01.2012 .929$

\begin{abstract}
The present study was designed to investigate whether cyclooxygenase (COX) inhibitors (coxibs) could prolong survival time by attenuating the tumor growth of ovarian cancer xenograft-bearing mice. Tumor growth and survival time were observed and compared in mice which were treated with a COX-1 inhibitor (SC-560) and a COX-2 inhibitor (celecoxib) every other day for a 21 day period from the day of tumor formation. The trial lasted a total of 121 days. The combination therapy resulted in statistically significant inhibition of tumor size compared with the control group $(\mathrm{P}<0.05)$. Additionally, single treatment of SC-560 or celecoxib significantly prolonged the mean survival time of mice compared with the control group $(\mathrm{P}<0.05)$. We suggest that COX-1 and COX-2 inhibitors may improve survival and inhibit tumor growth, and that the tumor growth inhibition by coxibs may be the contributing factor for the prolonged survival time in mouse xenograft models.
\end{abstract}

\section{Introduction}

Cyclooxygenase (COX) enzymes are key rate-limiting enzymes that catalyze prostaglandin (PG) synthesis from arachidonic acid. Two isoforms of COX enzymes have been identified and characterized. One of these forms, COX-1, is a housekeeping gene product that performs a homeostatic role and is expressed in a variety of tissues. The other isoform, COX-2, cannot be detected in the majority of normal tissues, but it can be induced by inflammatory stimuli including growth factors, cytokines and oncogenes. These two isoforms are encoded by two separate genes and exhibit distinct cell-specific expression, regulation and subcellular localization; however, they share similar structural and kinetic properties (1).

An expanding body of evidence demonstrates that COX-2 is overexpressed in a variety of malignancies including colorectal cancer (2,3), breast cancer (3), lung carcinoma (3) and ovarian

Correspondence to: Dr Wei Li, Department of Gynecology, Nanjing Medical University of Hangzhou Hospital, 261 Huan-sha, Hangzhou, Zhejiang 310006, P.R. China

E-mail: wei5901482@tom.com

Key words: ovarian cancer, cyclooxygenase inhibitors, mice, survival time cancer (4); while overexpression of COX-1 has been identified in human head and neck cancer (5) as well as ovarian cancer (6). Clinical and preclinical studies have indicated that COX-2 inhibitors are rapidly emerging as an excellent target for prevention and/or treatment of human cancers (7-10) due to their antiproliferative and antiangiogenic effects and their role in enhanced immune surveillance $(8,9)$. Few studies have also concluded that COX-1 inhibitors are able to reduce tumor growth by decreasing cell proliferation and accelerating apoptosis $(6,10)$. Additionally, COX-2 inhibitors have demonstrated potent life-prolonging effects in patients with esophageal and gastroesophageal junction cancer (11) and in various animal models of cancer $(12,13)$.

On the basis of these findings, it was concluded that COX inhibitors (coxibs) are well-established chemopreventative drugs. Thus, in this study, we hypothesize that coxibs should markedly improve survival in ovarian cancer in vivo, possibly through inhibiting tumor growth. To examine this possibility, we studied the potential effects of SC-560 and celecoxib on survival time and tumor growth in an ovarian cancer xenograft-bearing mouse model.

\section{Materials and methods}

Human ovarian tumors in nude mice. The human ovarian carcinoma cell line SKOV-3 was used to appraise whether SC-560 and/or celecoxib were able to prolong the survival time by inhibiting ovarian cancer growth. SKOV-3 was purchased from China Type Culture Collection and grown in the recommended media under standard conditions. SKOV-3 cells were implanted subcutaneously in the dorsal skin $\left(5 \times 10^{6}\right.$ cells $)$ of female athymic nude mice (BALB/cA, 40-45 days old). A tumor was successfully formed, and after three generations, a $1.5-\mathrm{mm}^{3}$ well-developed tumor tissue was inoculated subcutaneously into the right axillary region of the mice. Treatment was initiated when the tumor became visible (average volume, $118.24 \mathrm{~mm}^{3}$ ). Mice were randomly separated into five groups (with 12 mice in each group) depending on their allocated treatment: SC-560, celecoxib, SC-560/celecoxib (combination group), indomethacin or control. The experimental design is shown in Fig. 1. The study was approved by the ethics committee of Nanjing Medical University of Hangzhou Hospital, Hangzhou, China.

The COX-1-selective inhibitor (SC-560; Sigma-Aldrich, St. Louis, MO, USA), COX-2-selective inhibitor (celecoxib; 
Pfizer, New York, NY, USA), and nonselective coxib (indomethacin; Sigma-Aldrich) were administered via gavage in a $0.5 \mathrm{ml}$ suspension of $5 \%$ methylcellulose and $0.025 \%$ Tween-20 twice a day to achieve a dose of $6 \mathrm{mg} / \mathrm{kg} /$ day SC-560, $50 \mathrm{mg} / \mathrm{kg} /$ day celecoxib and $1 \mathrm{mg} / \mathrm{kg} /$ day indomethacin. The doses were selected for their specificity in inhibiting COX isotypes (14). The control group of mice were treated with sterile PBS ( $\mathrm{pH}$ 7.2), while the selected doses of coxibs were administered to the SC-560 alone, celecoxib alone, SC-560 in combination with celecoxib, indomethacin alone and the control group every other day for a period of 21 days, beginning on the day when the tumors became palpable. Mice were maintained on a standard diet and water was made freely available.

The tumor dimensions were measured twice a week using a linear caliper, and the tumor volume was calculated using the equation $\mathrm{V}\left(\mathrm{mm}^{3}\right)=1 / 2 \times \mathrm{a} \mathrm{x} \mathrm{b}^{2}$, where $\mathrm{a}$ and $\mathrm{b}$ are the largest and the smallest perpendicular diameters (15), respectively. These results are used to calculate the relative tumor volume (RTV) using the equation $\mathrm{RTV}=\mathrm{V}_{\mathrm{t}} / \mathrm{V}_{0}$, where $\mathrm{V}_{0}$ is tumor volume on the day of first administration and $\mathrm{V}_{\mathrm{t}}$ is the total for each measurement of tumor volume. The animals were weighed weekly throughout the experiment. In order to observe the effect of the coxibs on tumor growth, half of the mice in each group were sacrificed randomly on day 28 . All tumor tissue samples were then collected and fixed in $10 \%$ phosphate-buffered formalin solution for molecular biology or snap frozen in liquid nitrogen and stored at $-80^{\circ} \mathrm{C}$ for further analysis. The remaining mice were continually reared with a basal diet to observe the survival time, and the study was continued until all mice had been sacrificed (day 121).

Reverse transcription-polymerase chain reaction (RT-PCR). To investigate the expression of COX-1 and COX-2 mRNA levels in the human ovarian carcinoma cell line SKOV-3, the coxib treatment groups and the control group were analyzed for the expression of COX-1 and COX-2 mRNA using RT-PCR. Total RNA was isolated from the tissue using TRIzol reagent (Invitrogen Life Technologies, Carlsbad, CA, USA). Total RNA $(5 \mu \mathrm{g})$ was reverse transcribed using the SuperScript-II according to the manufacturer's protocol (Invitrogen Life Technologies). PCR for COX-1, COX-2 and $\beta$-actin was carried out in a 50- $\mu 1$ reaction mixture containing $5 \mu 1$ aliquots of reverse transcribed cDNA samples, 1 X PCR buffer, $1.5 \mathrm{mM}$ $\mathrm{MgCl}_{2}, 0.2 \mathrm{mM}$ dNTP, 2.5 units Ampi-Taq DNA polymerase and $400 \mathrm{nM}$ primers. PCR was run for 40 cycles, which consisting of denaturation at $94^{\circ} \mathrm{C}$ for $30 \mathrm{sec}$, annealing at $54^{\circ} \mathrm{C}$ for $30 \mathrm{sec}$, extension at $72^{\circ} \mathrm{C}$ for $45 \mathrm{sec}$ and final extension at $72^{\circ} \mathrm{C}$ for $5 \mathrm{~min}$. A constitutively expressed $\beta$-actin gene was used as a control with PCR conditions identical to that for COX-1 and COX-2. The primers for COX-1 were 5'-cctcaccagtcaatccctgt-3' (sense) and $5^{\prime}$-gggcagtctttgggtacaga-3' (antisense), and those for COX-2 were 5'-tcctcccgtagcaga tgact-3' (sense) and 5'-aagtggtaaccgctcaggtg-3' (antisense). The primers for $\beta$-actin were 5 '-ttgctgacaggatgcagaag-3' (sense) and 5'-acatctgctggaaggtggac-3' (antisense).

Statistical analyses. All results were expressed as the mean \pm standard error (SE). We used the Dunnett's test and the log-rank test based on the joint-ranking method for

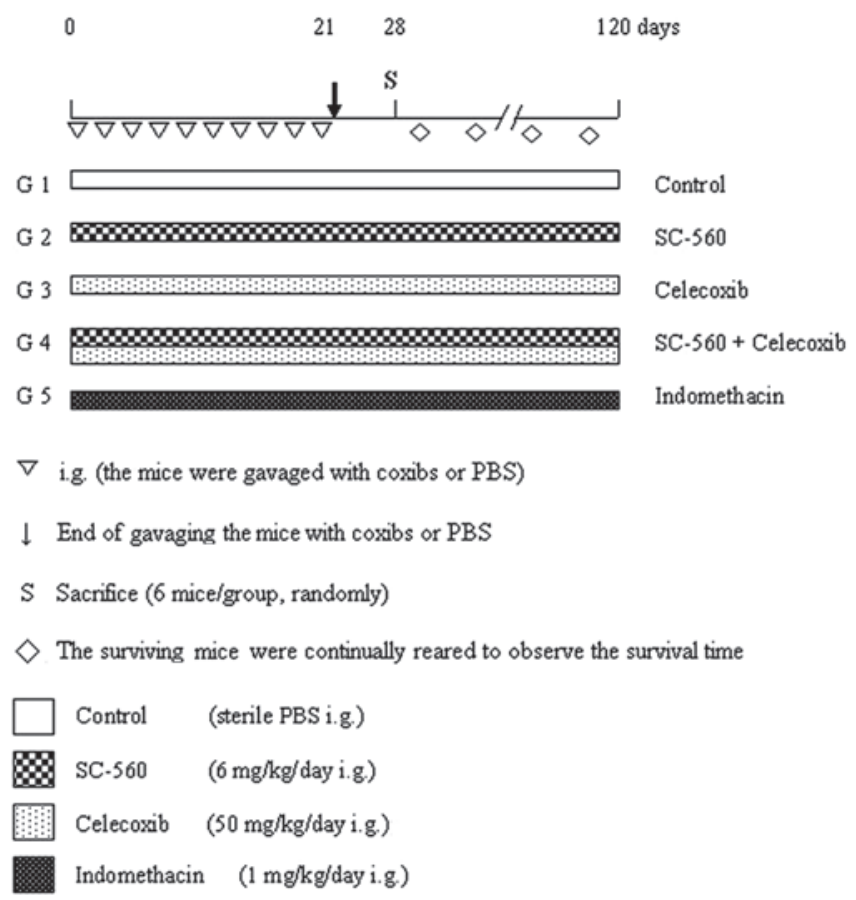

Figure 1. Experimental design. i.g., intragastric; coxibs, cyclooxygenase inhibitors; PBS, phosphate-buffered saline.

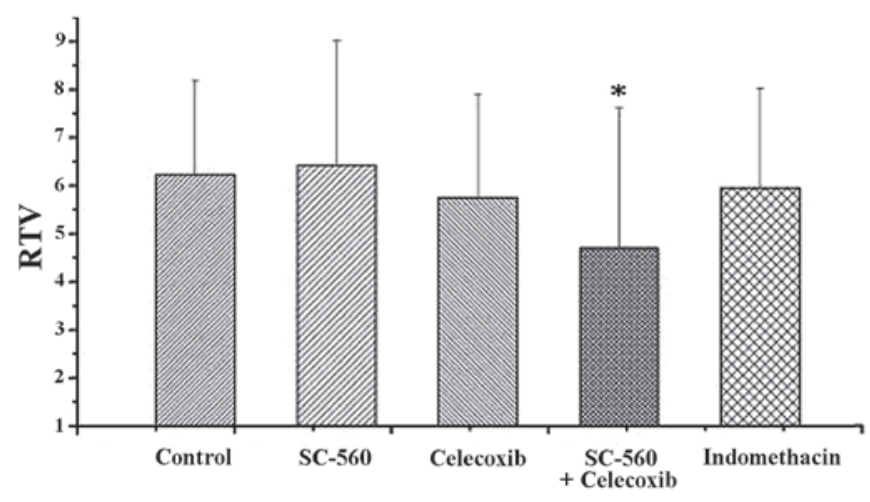

Figure 2. The RTV of the mice in each group (12 mice in each group) following three weeks of treatment with coxibs. Statistical significance was determined using the Dunnett's test. " $\mathrm{P}<0.05$ vs. control group. Error bars indicate SE. RTV, relative tumor volume; coxibs, cyclooxygenase inhibitors; SE, stardard error.

evaluation of the inhibitory activity on tumor growth and life-prolonging activity, respectively. Additionally, to evaluate the life-prolonging effect of the coxibs, the median survival time (MST; days) for each group following tumor inoculation was determined from the survival times of the mice according to the Kaplan-Meier plot using the SPSS system 17.0 (SPSS, Inc., Chicago, IL, USA). $\mathrm{P}<0.05$ was considered to indicate a statistically significant difference.

\section{Results}

Effect of coxibs on tumor growth. Following tumor establishment, 12 mice in each group were treated with SC-560, celecoxib, SC-560/celecoxib or indomethacin. Treatment was 


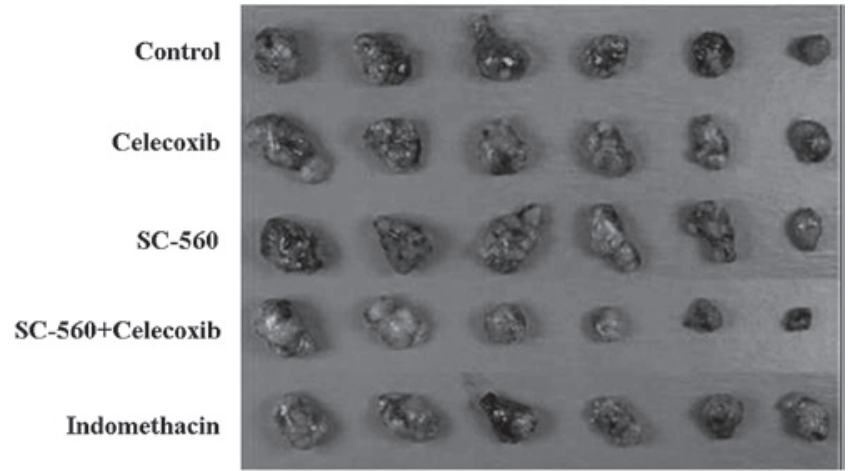

Figure 3. Tumor volumes of the mice sacrificed in the experiment were recorded. On day 28 , half of the mice in each group were sacrificed randomly, and tumor tissue samples were collected.

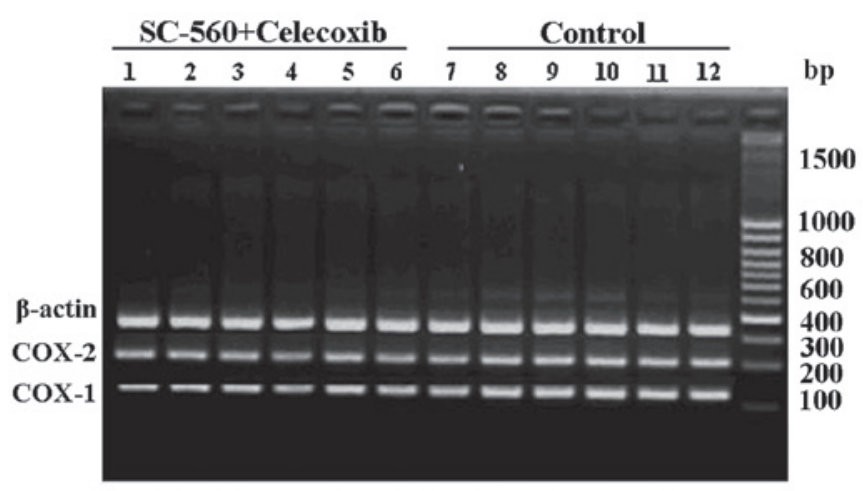

Figure 4 . On day 28 , six mice in each group were sacrificed randomly and tumor tissue samples were collected for molecular biology. RT-PCR was conducted to analyze the expression of COX-1 and COX-2 in these tumor samples treated with SC-560 plus celecoxib (Lanes 1-6) and in control group (lanes 7-12). Actin served as a control. RT-PCR, reverse transcription-polymerase chain reaction.

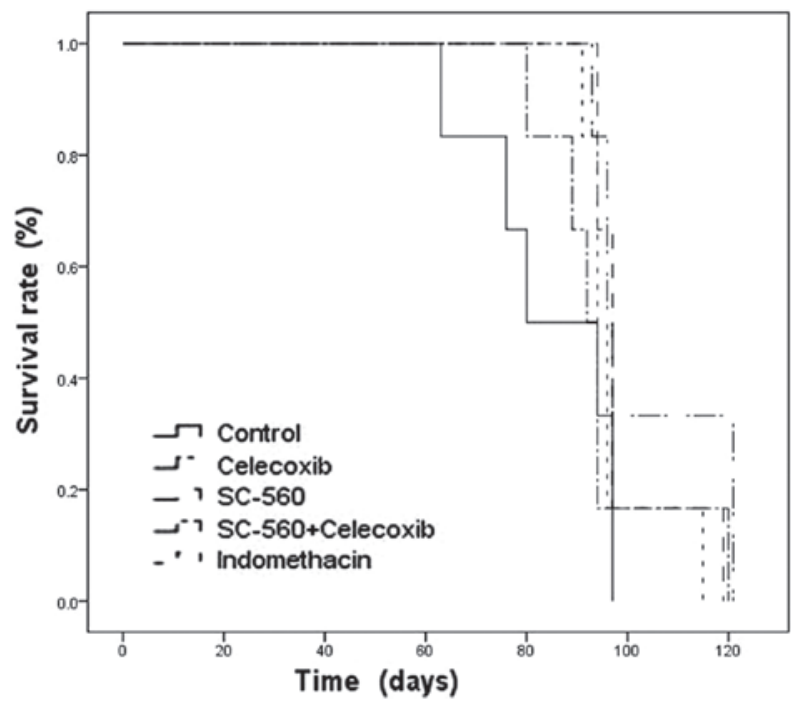

Figure 5. Kaplan-Meier curves for survival. The day when tumor tissues were inoculated into the mice is defined as day 0 . The statistical significance of differences in the survival curves between the groups were evaluated using the log-rank test.
Table I. Survival time in xenografted mice with ovarian cancer.

\begin{tabular}{lccc}
\hline & & \multicolumn{2}{c}{ Survival time (days) } \\
\cline { 3 - 4 } Group & $\begin{array}{c}\text { Sample } \\
\text { size }\end{array}$ & Mean $( \pm$ SD) & MST \\
\hline Control & 6 & $84.50 \pm 5.65$ & 87 \\
Celecoxib & 6 & $104.00 \pm 5.40^{\mathrm{a}}$ & 96.5 \\
SC-560 & 6 & $99.67 \pm 3.91^{\mathrm{a}}$ & 97 \\
SC-560+celecoxib & 6 & $94.83 \pm 5.47$ & 93 \\
Indomethacin & 6 & $97.67 \pm 3.55$ & 95.5 \\
\hline
\end{tabular}

Statistical significance was determined using the Dunnett's test. ${ }^{\text {aP }}<0.05$. MST, median survival time.

continued for 21 days. To examine whether the life-prolonging activities of COX-1 and COX-2 selective inhibitors were caused by their inhibitory effects on tumor growth, six randomly selected mice in each group were sacrificed on day 28. Tumor growth was evaluated by measuring the RTV, as shown in Fig. 2. On day 21, at the end of treatment, the RTV was $6.42 \pm 2.60$ in the SC-560 group. Under similar conditions, the RTVs were $4.69 \pm 2.93,5.75 \pm 2.15,5.96 \pm 2.07$ and $6.23 \pm 1.97$ in the SC560/celecoxib, celecoxib, indomethacin and control groups, respectively. Combination therapy resulted in a statistically significant inhibition of tumor size compared with the vehicle-treated control group $(\mathrm{P}<0.05)$. On day 28 , to assess the growth-inhibitory effect of coxibs, six randomly selected mice in each group were sacrificed, and tumor tissue samples were collected and photographed (Fig. 3). No toxicity was observed in any of the mice, as measured by weight gain/loss as well as gross pathological examination of the gastrointestinal tract of the mice at necropsy.

COX mRNA expression. To investigate whether the coxibs regulated COX-1 or COX-2 expression in ovarian carcinoma xenograft-bearing mice, all collected tumor tissue samples in the combination and control groups were analyzed for differential expression of COX-1 and COX-2 mRNA by RT-PCR analysis. The analysis revealed that following treatment with celecoxib and SC-560, the presence of COX-1 and COX-2 mRNA was reduced, while they were distinctly evident in untreated tumor samples (Fig. 4).

Effect of coxibs on survival. To observe the effect of coxibs in improving survival, after day 28 the remaining six mice continued to be reared with a standard diet and water. The mice were closely monitored and studies were terminated when all mice were sacrificed on day 121 due to the level of burden caused by the tumor. In the vehicle-treated control group, the first and last mice were sacrificed on days 63 and 97, respectively, and the mean survival time was $84.50 \pm 5.65$ days. In the coxibs-treated groups, the first mouse was sacrificed on day 80, as in the SC560+celecoxib group, and the last mouse was sacrificed on day 121, in the celecoxib group. The coxibs monotherapy or combination therapy groups resulted in a trend toward extending the survival time in comparison to the control group (Fig. 5). Celecoxib or SC-560 treat- 
ment alone markedly prolonged the mean survival time of xenograft-bearing mice in comparison with the control group $(\mathrm{P}<0.05$; Table I). Particularly in the celecoxib group, the mean survival time was extended to $104.00 \pm 5.40$ days. The last mouse to be sacrificed (on day 121) was also in this group. To evaluate the life-prolonging effect of coxibs, the MST for each group was determined. MST is the estimated time from diagnosis when $50 \%$ of the mice died, and is measured using the Kaplan-Meier estimate of survival. MST for each coxibtreated group was significantly longer in comparison with the vehicle treated control group (Table I).

\section{Discussion}

The present study was designed to assess whether coxibs are able to prolong the survival time of nude mice transplanted with the human ovarian cancer SKOV-3 cell line. This study revealed that the survival probability was extended following coxib therapy. Celecoxib or SC-560 treatment alone demonstrated a significantly prolonged mean survival time and MST in comparison with the control group in vivo.

Recent clinical studies have provided convincing evidence of poor survival in patients who demonstrated high COX-2 expression in stage IIB cervical adenocarcinoma and breast cancer $(16,17)$. Erkinheimo et al (18) suggested that elevated expression of COX-2 is associated with reduced survival in serous ovarian carcinomas. Another clinical study by Denkert et al (4) using univariate and multivariate analyses indicated that the expression of COX-2 in patients with ovarian carcinomas is a predictor of short survival times. Based on these findings, researchers have focused their attention on coxibs and survival in tumors. In a phase 2 trial, celecoxib treatment improved overall survival in patients who suffered from COX-2-positive esophageal and gastroesophageal junction cancer (11). In colorectal adenocarcinoma, CS-706, a novel COX-2 selective inhibitor, was demonstrated to have potent life-prolonging activity in tumor-bearing mice (12). In ovarian cancer, Xin et al (13) identified that meloxicam, categorized as a selective COX-2 inhibitor, prolonged survival in vivo when administered alone. However, studies concerning the correlation of COX-1 and survival are rarely reported. In the present study, we reveal that celecoxib and SC-560 prolong survival in a mouse xenograft model. Our results are similar to those of Sorenmo et al (19) which demonstrated that dogs with prostatic carcinoma treated with coxibs (piroxicam or carprofen) lived significantly longer than untreated dogs.

Additionally, we attempted to find the correlation between survival time and tumor growth. We examined the antitumor activity of coxibs on tumor growth, and we observed that a combination of SC-560 and celecoxib resulted in a significant inhibition of tumor size in comparison with the control group. In the same study (20), we identified that combined coxib therapy produced significant potential synergistic suppressive effects on tumor growth in comparison with the same doses of either SC-560 or celecoxib following 14 days of treatment. This was in accordance with the results from Kitamura et al (21) who revealed that combination therapy with mofezolac (a COX-1 selective inhibitor) and nimesulide (a COX-2 selective inhibitor) has particular potential for chemoprevention of colon carcinogenesis compared with the effects of either coxib as monotherapy.
In their study, the number of polyps more than $2.5 \mathrm{~mm}$ in diameter was markedly decreased by combined coxib treatment. We also observed that SC-560 or celecoxib, as a single agent, had a decreasing tendency in tumor growth, which was in accordance with other studies demonstrating SC-560 or celecoxib suppression of tumor growth in mouse models of ovarian cancer $(6,22)$. Taken together, we considered that coxibs were able to prolong survival time by attenuating tumor growth in ovarian cancer. We observed that suppressive effects on tumor growth were markedly exhibited following 14 days of treatment. For this reason, on day 28, six randomly selected mice from each group were sacrificed to observe the effect of coxibs on tumor growth, and the last six mice were reared to record the survival time. Our novel findings suggest that tumor growth was inhibited in each therapeutic group, which resulted in the prolonged survival of mice. Although multiple molecular and cellular mechanisms are involved in exerting the antitumor effects of coxibs, the mechanisms by which coxibs extend survival are currently unclear. Yao et al (23) suggested that selective or nonselective coxibs improved survival in mouse models of colorectal cancer by modulating tumor angiogenesis.

Increasing levels of COX-1 and COX-2 mRNA have been observed in ovarian cancer $(18,24)$. Several studies have reported that COX-1 and COX-2 are concurrently overexpressed and play an important role in the pathogenesis of ovarian cancer $(4,25)$. In the present study, RT-PCR results revealed that COX-1 and COX-2 mRNA expression levels were increased in untreated tumors, but were decreased in the combined treatment tumors. In the same study, using western blotting analysis, we identified that COX-1 and COX-2 protein levels were reduced in the combination group cells in comparison with those in the control group (20). The reason for the inhibition of COX-1 and/or COX-2 mRNA and protein expression in neoplastic tissues may be due to the inhibition of angiogenesis, induction of apoptosis and/or antiproliferative effects $(6,8,10)$. The antitumor effects of coxibs have long been suggested to depend on the inhibition of COX activity and PG synthesis. $\mathrm{PGE}_{2}$ is produced from arachidonic acid by one of two enzymes: COX-1 or COX-2. There is increasing evidence that $\mathrm{PGE}_{2}$ contributes to tumor progression by promoting tumor angiogenesis and inducing tumor cell apoptosis $(8,26,27)$. Our same study that focused on the potential mechanisms revealed that coxibs suppress ovarian tumor growth by influencing cell proliferation and apoptosis (20). These results suggest that the inhibition of COX-1 and/or COX-2 is able to slow tumor growth, the beneficial effects of which may prolong survival time.

In conclusion, the present study suggests that the prolonged survival of coxib-treated animals is most likely the result of suppressing tumor growth through multiple mechanisms, including antiproliferative and apoptosis effects in vivo. However, the exact mechanism of life-prolonging activity requires further study.

\section{References}

1. Smith WL, Garavito RM and DeWitt DL: Prostaglandin endoperoxide $\mathrm{H}$ synthases (cyclooxygenases)-1 and -2. J Biol Chem 271: 33157-33160, 1996.

2. Gupta RA and Dubois RN: Colorectal cancer prevention and treatment by inhibition of cyclooxygenase-2. Nat Rev Cancer 1: 11-21, 2001. 
3. Soslow RA, Dannenberg AJ, Rush D, Woerner BM, Khan KN Masferrer J and Koki AT: COX-2 is expressed in human pulmonary, colonic, and mammary tumors. Cancer 89: 2637-2645, 2000.

4. Denkert C, Kobel M, Pest S, Koch I, Berger S, Schwabe M, Siegert A, Reles A, Klosterhalfen B and Hauptmann S: Expression of cyclooxygenase 2 is an independent prognostic factor in human ovarian carcinoma. Am J Pathol 160: 893-903, 2002.

5. Erovic BM, Woegerbauer M, Pammer J, Selzer E, Grasl MCh and Thurnher D: Strong evidence for up-regulation of cyclooxygenase-1 in head and neck cancer. Eur J Clin Invest 38: 61-66, 2008.

6. Daikoku T, Wang D, Tranguch S, Morrow JD, Orsulic S, Dubois RN and Dey SK: Cyclooxygenase-1 is a potential target for prevention and treatment of ovarian epithelial cancer. Cancer Res 65: 3735-3744, 2005.

7. Steinbach G, Lynch PM, Phillips RK, Wallace MH, Hawk E, Gordon GB, Wakabayashi N, Saunders B, Shen Y, Fujimura T, Su LK and Levin B: The effect of celecoxib, a cyclooxygenase-2 inhibitor, in familial adenomatous polyposis. N Engl J Med 342: 1946-1952, 2000.

8. Ragel BT, Jensen RL, Gillespie DL, Prescott SM and Couldwell WT: Celecoxib inhibits meningioma tumor growth in a mouse xenograft model. Cancer 109: 588-597, 2007.

9. Yao M, Kargman S, Lam EC, Kelly CR, Zheng Y, Kwong E, Evans JF and Wolfe MM: Inhibition of cyclooxygenase- 2 by rofecoxib attenuates the growth and metastatic potential of colorectal carcinoma in mice. Cancer Res 63: 586-592, 2003.

10. Urick ME, Giles JR and Johnson PA: VEGF expression and the effect of NSAIDs on ascites cell proliferation in the hen model of ovarian cancer. Gynecol Oncol 110: 418-424, 2008.

11. Altorki NK, Christos P, Port JL, Lee PC, Mirza F, Spinelli C, Keresztes R, Beneck D, Paul S, Stiles BM, Zhang Y and Schrump DS: Preoperative taxane-based chemotherapy and celecoxib for carcinoma of the esophagus and gastroesophageal junction: results of a phase 2 trial. J Thorac Oncol 6: 1121-1127, 2011.

12. Senzaki M, Ishida S, Yada A, Hanai M, Fujiwara K, Inoue $S$, Kimura T and Kurakate S: CS-706, a novel cyclooxygenase-2 selective inhibitor, prolonged the survival of tumor-bearing mice when treated alone or in combination with anti-tumor chemotherapeutic agents. Int J Cancer 122: 1384-1390, 2008.

13. Xin B, Yokoyama Y, Shigeto T and Mizunuma H: Anti-tumor effect of non-steroidal anti-inflammatory drugs on human ovarian cancers. Pathol Oncol Res 13: 365-369, 2007.

14. Reese J, Zhao X, Ma WG, Brown N, Maziasz TJ and Dey SK: Comparative analysis of pharmacologic and/or genetic disruption of cyclooxygenase- 1 and cyclooxygenase- 2 function in female reproduction in mice. Endocrinology 142: 3198-3206, 2001.

15. Williams CS, Watson AJ, Sheng H, Helou R, Shao J and Dubois RN: Celecoxib prevents tumor growth in vivo without toxicity to normal gut: lack of correlation between in vitro and in vivo models. Cancer Res 60: 6045-6051, 2000.
16. Jung YW, Kim SW, Kim S, Kim JH, Cho NH, Kim JW and Kim YT: Prevalence and clinical relevance of cyclooxygenase-1 and -2 expression in stage IIB cervical adenocarcinoma. Eur J Obstet Gynecol Reprod Biol 148: 62-66, 2010.

17. Glynn SA, Prueitt RL, Ridnour LA, Boersma BJ, Dorsey TM, Wink DA, Goodman JE, Yfantis HG, Lee DH and Ambs S: COX-2 activation is associated with Akt phosphorylation and poor survival in ER-negative, HER2-positive breast cancer. BMC Cancer 10: 626, 2010.

18. Erkinheimo TL, Lassus H, Finne P, van Rees BP, Leminen A, Ylikorkala O, Haglund C, Butzow R and Ristimäki A: Elevated cyclooxygenase-2 expression is associated with altered expression of p53 and SMAD4, amplification of HER-2/neu, and poor outcome in serous ovarian carcinoma. Clin Cancer Res 10: 538-545, 2004.

19. Sorenmo KU, Goldschmidt MH, Shofer FS, Goldkamp C and Ferracone J: Evaluation of cyclooxygenase-1 and cyclooxygenase-2 expression and the effect of cyclooxygenase inhibitors in canine prostatic carcinoma. Vet Comp Oncol 2: 13-23, 2004.

20. Li W, Wang J, Jiang HR, Xu XL, Zhang J, Liu ML and Zhai LY: Combined effects of cyclooxygenase- 1 and cyclooxygenase- 2 selective inhibitors on ovarian carcinoma in vivo. Int J Mol Sci 12: 668-681, 2011.

21. Kitamura T, Itoh M, Noda T, Matsuura M and Wakabayashi K: Combined effects of cyclooxygenase- 1 and cyclooxygenase- 2 selective inhibitors on intestinal tumorigenesis in adenomatous polyposis coli gene knockout mice. Int J Cancer 109: 576-580, 2004.

22. Li W, Jiang HR, Xu XL, Wang J, Zhang J, Liu ML and Zhai LY: Cyclin D1 expression and the inhibitory effect of celecoxib on ovarian tumor growth in vivo. Int J Mol Sci 11: 3999-4013, 2010.

23. Yao M, Zhou W, Sangha S, Albert A, Chang AJ, Liu TC and Wolfe MM: Effects of nonselective cyclooxygenase inhibition with low-dose ibuprofen on tumor growth, angiogenesis, metastasis, and survival in a mouse model of colorectal cancer. Clin Cancer Res 11: 1618-1628, 2005.

24. Hales DB, Zhuge Y, Lagman JA, Ansenberger K, Mahon C, Barua A, Luborsky JL and Bahr JM: Cyclooxygenases expression and distribution in the normal ovary and their role in ovarian cancer in the domestic hen (Gallus domesticus). Endocrine 33: 235-244, 2008.

25. Spinella F, Rosano L, Di Castro V, Nicotra MR, Natali PG and Bagnato A: Inhibition of cyclooxygenase- 1 and -2 expression by targeting the endothelin a receptor in human ovarian carcinoma cells. Clin Cancer Res 10: 4670-4679, 2004.

26. Sheng H, Shao J, Morrow JD, Beauchamp RD and DuBois RN: Modulation of apoptosis and $\mathrm{Bcl}-2$ expression by prostaglandin E2 in human colon cancer cells. Cancer Res 58: 362-366, 1998.

27. Masferrer JL, Leahy KM, Koki AT, Zweifel BS, Settle SL, Woerner BM, Edwards DA, Flickinger AG, Moore RJ and Seibert K: Antiangiogenic and antitumor activities of cyclooxygenase-2 inhibitors. Cancer Res 60: 1306-1311, 2000. 